\title{
As Ciências da Terra na disciplina de Ciências Naturais do ensino básico em Portugal
}

\author{
Earth Sciences in the discipline of Natural Sciences of basic education in Portugal \\ Jorge Bonito ${ }^{1}$, Margarida Morgado ${ }^{2}$ \\ 1 Univ. Évora; Centro de Investigação "Didática e Tecnologia na Formação de Formadores” (CIDTFF) da univ. Aveiro, Portugal. jbonito@uevora.pt \\ 2 Escola Secundária de Viriato, Viseu, Portugal. - morgadommargarida@gmail.com
}

ABSTRACT: The literacy in Earth Sciences of a citizen who completes basic education is now considered as an essential objective in order to formulate value judgments and make decisions about the problems that arise daily in the society in which he lives. Based on the key ideas of a Spanish Commission, created to identify the basic knowledge items in Earth Sciences, a synopsis is made with the curricular goals for Portuguese basic education related to Earth Sciences contents. The analysis shows that Portugal has set learning objectives for basic education that places it at the forefront of the proposals within the key ideas established by the aforementioned Commission.

\section{Manuscrito:}

Recebido: 23/05/2017

Corrigido: 06/09/2017

Aceito: $31 / 10 / 2017$

Citation: Bonito J., Morgado M. 2017. As Ciências da Terra na disciplina de Ciências Naturais do ensino básico em Portugal. Terræ Didatica, 13(3):258-270. <http://www.ige.unicamp. $\mathrm{br} /$ terraedidatica/>

Keywords: Literacy, Geoscience education, curricular goals, basic education.

\section{Introdução}

As Ciências da Terra são, modernamente, um campo em plena efervescência, incorporando conhecimentos de outras áreas do saber, aumentando gradativamente, em alguns campos e escalas, a sua capacidade preditiva (Barton \& La Pointe 1995, Srivastava et al. 2017). São, por isso, um campo imprescindível para apontarem soluções para muitos dos problemas da sociedade atual e indicarem caminhos para algumas inquietudes que se vivem quotidianamente (Stewart \& Gill 2017). Dispor de uma perspetiva temporal adequada sobre as alterações que afetaram a Terra, relacionar as principais interações entre a ação antrópica e o planeta e ser capaz de ter uma visão e uma atuação que garanta a sustentabilidade da vida das gerações futuras parecem ser objetivos para a formação de uma pessoa literata em Ciências da Terra. De acordo com a UNESCO, "todas as decisões sobre a sustentabilidade deveriam estar fundamentadas na riqueza do conhecimento, existente e futuro, proporcionado pelas Ciências da Terra" (Unesco 2008:1). Tem vindo a constituir consenso na comunidade de geólogos e de educadores em Ciências da Terra que o cidadão deve compreender o funcionamento do planeta Terra, através de uma educação básica, que lhe permita pensar, formular juízos e tomar decisões fundamentadas e em consciência e (NESTA 2015, GSA 2016).

Tendo por base o reconhecimento da importância das Ciências da Terra na sociedade atual, várias sociedades científicas e organizações espanholas constituíram uma comissão ad hoc com o intuito de refletir, discutir e definir a literacia em Ciências da Terra do aluno que conclua a escolaridade obrigatória. Foram formuladas dez ideias-chave que sintetizam esses conhecimentos básicos e os conceitos, princípios e teorias que as sustentam (Pedrinaci et al. 2013), cada uma com várias sub-ideias-chave (num total de 79): 1 - A Terra é um sistema complexo em que interagem as rochas, a água, o ar e a vida; 2 - A origem da Terra está ligada à do Sistema Solar e a sua longa história encontra-se registada nos materiais que a compõem; 3 - Os materiais da Terra originam-se e modificam-se de forma contínua; 4 - $A$ água e o ar fazem da Terra um planeta especial; 5 - A vida evolui e interage com a Terra modificando-a mutuamente; $6-A$ tectónica de placas é uma teoria global e integradora da Terra; 7 - Os processos geológicos externos transformam a superficie terrestre; 8-A humanidade depende do planeta Terra para a obtenção dos seus recursos e deve fazê-lo de modo sustentável; 9 - Alguns processos naturais implicam riscos para a humanidade; 10 - Os cientistas interpretam 
e explicam o funcionamento da Terra baseando-se em observações repetíveis e em ideias verificáveis.

A proposta de alfabetização em Ciências da Terra elaborada por Pedrinaci et al. (2013) foi possível graças ao esforço conjunto de praticamente todas as sociedades científicas espanholas relacionadas com as Ciências da Terra e a Educação. Os autores pretenderam proporcionar à administração educativa um guia para a elaboração de curricula em Ciências da Terra na escolaridade básica e aos professores uma referência para o seu tratamento na sala de aula.

Em Portugal, o ensino básico ${ }^{1}$ é orientado por metas curriculares nas quais são definidos, de forma consistente, os conhecimentos e as capacidades essenciais que os alunos devem adquirir nos diferentes anos de escolaridade e nos conteúdos dos respetivos programas (Despacho n. ${ }^{\circ}$ 5306/2012, de 2 de abril). As metas curriculares, que incluem conteúdos das Ciências da Terra, foram homologadas em março de 2013 (Ministério da Educação 2013), constituindo-se, deste modo, como uma referência fundamental no ensino.

Mais recentemente, o Ministério da Educação (2017) apresentou as "aprendizagens essenciais" destinadas às escolas abrangidas pelo projeto de autonomia e flexibilidade curricular. Procurou-se, deste modo, identificar para cada disciplina o conjunto de conteúdos, capacidades e atitudes que consolidem aprendizagens de modo efetivo, desenvolvam competências que requerem mais tempo e permitam uma efetiva diferenciação pedagógica em sala de aula. Tal definição não implica qualquer revogação das metas.

Os temas de Ciências da Terra no ensino básico estudados são os que a seguir se indicam (Tabs. 1 a 10): i) Disciplina de Estudo do Meio (1. ${ }^{\circ}$ ciclo) - Água $\left(1 .^{\circ}-4 .^{\circ}\right.$ anos), Rochas $\left(3 .^{\circ}-4 .^{\circ}\right.$ anos), Solo (1. ${ }^{\circ}, 3 .{ }^{\circ}-4 .^{\circ}$ anos), Relevo (3..$^{\circ}$ ano) e Astros (3. ${ }^{\circ}-4 .^{\circ}$ anos); ii) Disciplina de Ciências Naturais (2. ${ }^{\circ}$ ciclo) - Solo, Rochas, Água (5. ${ }^{\circ}$ ano); iii) Disciplina de

\footnotetext{
1 Em Portugal, 0 ensino básico visa assegurar uma formação geral comum a todos os cidadãos, proporcionando a aquisição dos conhecimentos basilares que permitam o prosseguimento de estudos (art. $4 .^{0}$, n. $^{0} 1$ do Decreto-Lei n. ${ }^{0}$ 139/2012, de 5 de julho). 0 ensino básico é universal, obrigatório e gratuito (abrange taxas e emolumentos relacionados com a matrícula, frequência e certificação, podendo ainda os alunos dispor gratuitamente do uso de manuais e material escolar, bem como de transporte, alimentação e alojamento, quando necessários). Tem a duração de 9 anos. Compreende três ciclos sequenciais: 0 primeiro de quatro anos (6-10 anos de idade), o segundo de dois anos (10-12 anos de idade) e 0 terceiro de três anos (12-15 anos de idade). $02{ }^{\circ}{ }^{\circ}$ ciclo do ensino básico organiza-se por áreas interdisciplinares de formação básica. Em geral há um professor por área disciplinar. $03 .{ }^{\circ}$ ciclo do ensino básico organiza-se segundo um plano curricular unificado, desenvolvendo-se no regime de um professor por disciplina ou grupo de disciplinas.
}

Ciências Naturais (3. ${ }^{\circ}$ ciclo)- Dinâmica externa da Terra; Estrutura, dinâmica interna da Terra e suas consequências; História da Terra; Ciência geológica e a sustentabilidade da vida na Terra (7. ${ }^{\circ}$ ano); Sustentabilidade na Terra, Gestão sustentável dos recursos ( $8 .^{\circ}$ ano). Todavia, apenas se encontram definidas metas curriculares para o $2 .^{\circ}$ e $3 .^{\circ}$ ciclos do ensino básico (Bonito 2014).

A definição das ideias-chave apresentadas por Pedrinaci et al. (2013) e as metas curriculares para o ensino básico, em Portugal, não são suficientes, por si mesmas, para uma alteração das práticas curriculares. "Os professores constituem, mais do que ninguém, a chave da mudança educativa" (Hargreaves 1998:12). Os conteúdos curriculares e os objetivos operacionais são elementos estruturantes no processo de ensino e aprendizagem, mas ao professor cabe "deixar a sua lição magistral para se dedicar à orientação do aluno, no que diz respeito ao seu desenvolvimento pessoal e social. Uma orientação que medeia entre o conhecimento e o aluno, e estimula, motiva e diagnostica necessidades individuais de cada um, em particular, para poder ajudar a construir o conhecimento sobre o mundo natural" (Bonito 2012, p. 20). A investigação e a reflexão sobre a prática são, pois, dois fatores muito importantes que impulsionam o sucesso profissional do professor e as aprendizagens eficazes dos alunos. Ambas permitem a tomada de consciência das ideias e dos comportamentos, confrontar vários pontos de vista, e tomar as necessárias decisões sobre o que deve ser mudado.

O objetivo deste trabalho foi realizar uma análise sinótica entre as ideias-chave da comissão ad hoc espanhola (Pedrinaci et al. 2013) e as metas curriculares para a disciplina de Ciências Naturais (Ministério da Educação 2013), procurando situar curricularmente a política educativa portuguesa relativamente ao ensino das Ciências da Terra (Tabs. 1 a 10).

\section{Análise sinótica}

$\mathrm{Na}$ análise sinótica efetuada, e apresentada nas tabelas (Tabs. 1 a 10), são tidas em conta as ideias-chave e as sub-ideias consideradas fundamentais para a literacia científica do aluno que completa o ensino básico e as metas curriculares da disciplina de Ciências Naturais do sistema educativo português que contemplam conteúdos das Ciências da Terra. $\mathrm{Na}$ coluna da esquerda apresentam-se as sub-ideias para a literacia científica do aluno explicitadas pela 
comissão ad hoc espanhola (Pedrinaci et al. 2013). Na coluna da direita identificam-se os objetivos gerais (por exemplo, 2) e os descritores - objetivos operacionais (por exemplo, 2.1) das metas curriculares da disciplina de Ciências Naturais. Entre parêntesis, à frente de cada objetivo / descritor, é indicado o ano de escolaridade em que os correspondentes objetivos gerais e/ou os descritores são lecionados. Quando se indica apenas o objetivo geral, por questão de economia de espaço, não são apresentados os respetivos descritores, pelo que se sugere a leitura destes diretamente a partir de Ministério da Educação (2013).

\section{A Terra é um sistema complexo no qual interagem as rochas, a água, 0 ar $\mathrm{e}$ a vida}

$\mathrm{Na}$ Tab. 1 apresentam-se, em sinopse, os objetivos / descritores das metas curriculares com correspondência à ideia-chave A terra é um sistema complexo em que interagem as rochas, a água, o ar e a vida.

Pela análise da Tab. 1 constata-se que na lecionação da disciplina de Ciências Naturais (Ministério da Educação 2013) são abordadas temáticas, em diferentes anos de escolaridade (5. ${ }^{\circ},{ }^{\circ}{ }^{\circ}$ e $8 .^{\circ}$ anos), que contribuem para que os alunos tenham a perceção de que o planeta Terra é um sistema complexo que resulta da interação das rochas, da água, do ar e da vida. Tendo por base esta abordagem, os alunos poderão entender o modo com funciona o planeta Terra, algumas das principais interações entre o ser humano e o planeta e os riscos naturais que o podem afetar, sensibilizando-os para a necessidade de contribuírem para a sua preservação.

\section{A origem da Terra está associada à do Sistema Solar e a sua longa história está registada nos materiais que a compõem}

A ideia-chave dois - A origem da Terra está ligada à do Sistema Solar e sua longa história encontra-se registada nos materiais que a compõem - inclui oito sub-ideias, baseando-se na abordagem da Terra como um sistema, com os seus vários subsistemas, que interagem entre si (Tab. 2).

Tabela 1. Análise sinótica entre a ideia-chave A Terra é um sistema complexo em que interagem as rochas, a água, o ar e a vida e as metas curriculares para a disciplina de Ciências Naturais

\begin{tabular}{|c|c|c|}
\hline \multicolumn{2}{|c|}{$\begin{array}{c}\text { Ideia-chave 1: A Terra é um sistema complexo em que } \\
\text { interagem as rochas, a água, o ar e a vida } \\
\text { (Pedrinaci et al. 2013) }\end{array}$} & $\begin{array}{l}\text { Metas curriculares de Ciências Naturais }{ }^{1} \\
\text { (Ministério da Educação 2013) }\end{array}$ \\
\hline \multirow{10}{*}{ 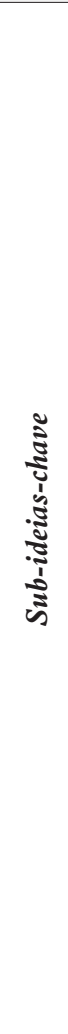 } & $\begin{array}{r}\text { 1.1. A consideração da Terra como um sistema } \\
\text { ajuda a entender como funciona este planeta }\end{array}$ & 2.2. Reconhecer a Terra como um sistema. $\left(8^{\circ}\right.$ ano $)$ \\
\hline & $\begin{array}{l}\text { 1.2. O sistema Terra está formado por quatro } \\
\text { subsistemas: geosfera, hidrosfera, atmosfera } \\
\text { e biosfera. }\end{array}$ & \multirow{5}{*}{$\begin{array}{l}\text { 1. Compreender a Terra como um planeta especial. }\left(5 .^{\circ}\right. \\
\text { ano) } \\
\text { 2.1. Descrever a Terra como um sistema composto } \\
\text { por subsistemas fundamentais (atmosfera, hidrosfera, } \\
\text { geosfera, biosfera). }\left(8 .^{\circ} \text { ano) }\right.\end{array}$} \\
\hline & $\begin{array}{l}\text { 1.3. Todos os processos da Terra são resultado } \\
\text { dos fluxos de energia e ciclos de matéria dentro } \\
\text { e entre os subsistemas terrestres. }\end{array}$ & \\
\hline & $\begin{array}{l}\text { 1.4. A Terra estabelece trocas de energia e de } \\
\text { matéria com o resto do Sistema Solar. }\end{array}$ & \\
\hline & $\begin{array}{l}\text { 1.5. Os subsistemas terrestres interagem num } \\
\text { amplo espetro de escalas espaciais e temporais. }\end{array}$ & \\
\hline & 1.6. Os subsistemas da Terra são dinâmicos. & \\
\hline & $\begin{array}{l}\text { 1.7. O clima é um exemplo de como as intera- } \\
\text { ções complexas entre os subsistemas terrestres } \\
\text { podem ocasionar mudanças imprevisíveis e } \\
\text { significativas. }\end{array}$ & $\begin{array}{l}\text { 1.3. Interpretar gráficos da evolução da temperatura, da } \\
\text { energia solar e do dióxido de carbono atmosférico ao } \\
\text { longo do tempo geológico. }\left(8 .^{\circ} \text { ano) }\right.\end{array}$ \\
\hline & \multirow{3}{*}{$\begin{array}{l}\text { 1.8. A atividade humana está a alterar o planeta } \\
\text { Terra. }\end{array}$} & $\begin{array}{l}\text { 15. Compreender o contributo do conhecimento } \\
\text { geológico para a sustentabilidade da vida na Terra. ( } 7 \text {. }^{\circ} \\
\text { ano) }\end{array}$ \\
\hline & & $\begin{array}{l}\text { 11.2. Descrever as causas das principais catástrofes de } \\
\text { origem antrópica. ( } 8 .^{\circ} \text { ano) }\end{array}$ \\
\hline & & $\begin{array}{l}\text { 11.3. Extrapolar o modo como a poluição, a } \\
\text { desflorestação, os incêndios e as invasões biológicas } \\
\text { afetam o equilíbrio dos ecossistemas. }\left(8^{\circ} \text { ano) }\right.\end{array}$ \\
\hline
\end{tabular}

1 Os números antes de cada descritor correspondem à numeração original das metas curriculares (Ministério da Educação, 2013). 
Tabela 2. Análise sinótica da ideia-chave A origem da Terra está ligada à do Sistema Solar e sua longa história encontrase registada nos materiais que a compõem e as metas curriculares para a disciplina de Ciências Naturais

\begin{tabular}{|c|c|c|}
\hline \multicolumn{2}{|c|}{$\begin{array}{l}\text { Ideia-chave 2: A origem da Terra está ligada à do Sis- } \\
\text { tema Solar e sua longa história encontra-se registada } \\
\text { nos materiais que a compõem }\end{array}$} & $\begin{array}{l}\text { Metas curriculares de Ciências Naturais }{ }^{1} \\
\text { (Ministério da Educação 2013) }\end{array}$ \\
\hline \multirow{7}{*}{ 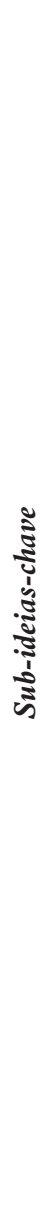 } & $\begin{array}{l}2.1 \text { As rochas e outros materiais terrestres } \\
\text { proporcionam um registo da história da } \\
\text { Terra. }\end{array}$ & $\begin{array}{l}\text { 1. Compreender a diversidade das paisagens geológicas. }\left(7 .^{\circ}\right. \\
\text { ano) } \\
\text { 3. Analisar os conceitos e os processos relativos à formação } \\
\text { das rochas sedimentares. ( } 7 .^{\circ} \text { ano) } \\
\text { 7. Interpretar a formação das rochas magmáticas. }\left(7 .^{\circ} \text { ano) }\right. \\
\text { 8. Compreender o metamorfismo como uma consequência } \\
\text { da dinâmica interna da Terra. ( } 7 .^{\circ} \text { ano) } \\
\text { 13. Compreender a importância dos fósseis para a } \\
\text { reconstituição da história da Terra. }\left(7 .^{\circ} \text { ano) }\right.\end{array}$ \\
\hline & $\begin{array}{l}\text { 2.2. O Sistema Solar originou-se a partir de } \\
\text { uma imensa nuvem de gás e de poeiras. } \\
\text { 2.3. A Terra formou-se há cerca de } 4.600 \\
\text { Ma por meio de múltiplas colisões de cor- } \\
\text { pos planetários mais pequenos. }\end{array}$ & $\begin{array}{l}\text { Conteúdo lecionado na disciplina de Ciências Físico-Quí- } \\
\text { micas. }\end{array}$ \\
\hline & $\begin{array}{l}\text { 2.4. A Terra é um dos planetas pequenos, } \\
\text { densos e rochosos do Sistema Solar. }\end{array}$ & $\begin{array}{l}\text { 1.1. Identificar a posição da Terra no Sistema Solar, por meio } \\
\text { de representações esquemáticas. }\left(8 .^{\circ} \text { ano }\right)\end{array}$ \\
\hline & $\begin{array}{l}\text { 2.5. Na primeira etapa da evolução da Terra } \\
\text { ocorreu a sua diferenciação e a sua estrutu- } \\
\text { ração em camadas. }\end{array}$ & \multirow[t]{2}{*}{ 12. Compreender a estrutura interna da Terra. $\left(7 .^{\circ}\right.$ ano) } \\
\hline & $\begin{array}{l}\text { 2.6. As característica da crusta terrestre são o } \\
\text { resultado da evolução geológica da Terra. }\end{array}$ & \\
\hline & $\begin{array}{l}\text { 2.7. O conhecimento do passado terrestre } \\
\text { ajuda a compreender o presente e permite } \\
\text { fazer previsões fundamentadas sobre o fu- } \\
\text { turo. }\end{array}$ & \multirow{2}{*}{$\begin{array}{l}\text { 14. Compreender as grandes etapas da história da Terra. }\left(7 .^{\circ}\right. \\
\text { ano) }\end{array}$} \\
\hline & $\begin{array}{l}\text { 2.8. A escala do tempo geológico constitui } \\
\text { um marco temporal no qual se interliga a } \\
\text { evolução histórica da Terra. }\end{array}$ & \\
\hline
\end{tabular}

Decorrente da análise da Tabela 2 torna-se explícito que na disciplina de Ciências Naturais (Ministério da Educação 2013) são abordadas temáticas, em diferentes anos de escolaridade $\left(7 .^{\circ}\right.$ e $8 .^{\circ}$ anos), que contribuem para que os alunos tenham a perceção de que a formação do Sistema Solar ocorreu há muitos milhões de anos e que no decorrer da sua evolução se formou o planeta Terra, que passou por um processo de evolução lento e gradual. As evidências de tais processos resultam de constatações que advêm de diferentes áreas do conhecimento (por exemplo, Física, Química, Ciências da Terra) e são, também, observadas em alguns tipos de rochas, constituindo-se como dados importantes que permitem contar a história da Terra.

\section{Os materiais da Terra originam-se e modificam-se de forma contínua}

A ideia-chave três - Os materiais terrestres originam-se e modificam-se continuamente" - inclui dez sub-ideias, baseando-se na abordagem da Terra como um sistema, com os seus vários subsistemas, que interagem entre si (Tab. 3).

A análise da Tab. 3 permite contatar que na lecionação da disciplina de Ciências Naturais (Ministério da Educação 2013) são abordadas temáticas, em diferentes anos de escolaridade $\left(5 .^{\circ}\right.$ e 7. ${ }^{\circ}$ anos), que permitem que os alunos tenham a perceção de que o planeta Terra é constituído por materiais rochosos que se vão formando e modificando de modo constante, como resultado de fenómenos de geodinâmica interna e externa. 
Tabela 3. Análise sinótica da ideia-chave Os materiais terrestres originam-se e modificam-se continuamente e das metas curriculares para a disciplina de Ciências Naturais

\begin{tabular}{|c|c|c|}
\hline \multicolumn{2}{|c|}{$\begin{array}{l}\text { Ideia-chave 3: Os materiais terrestres originam-se e } \\
\text { modificam-se continuamente } \\
\text { (Pedrinaci et al. 2013) }\end{array}$} & $\begin{array}{l}\text { Metas curriculares de Ciências Naturais }{ }^{1} \\
\text { (Ministério da Educação 2013) }\end{array}$ \\
\hline \multirow{10}{*}{ 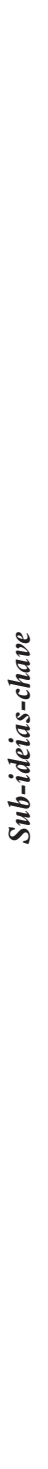 } & $\begin{array}{l}\text { 3.1 A Terra é formada, maioritariamente, por } \\
\text { materiais rochosos cujos constituintes básicos } \\
\text { são os minerais. }\end{array}$ & $\begin{array}{l}\text { 3. Compreender a importância das rochas e dos } \\
\text { minerais. }\left(5 .^{\circ} \text { ano) }\right. \\
\text { 2. Compreender os minerais como unidades básicas } \\
\text { das rochas. ( } 7 .^{\circ} \text { ano) }\end{array}$ \\
\hline & $\begin{array}{l}\text { 3.2. Os elementos químicos mais abundantes } \\
\text { nas rochas e nos minerais da crusta terrestre são } \\
\text { o oxigénio, o silício e o alumínio. }\end{array}$ & $\begin{array}{l}\text { Conteúdo programático lecionado na disciplina de Bio- } \\
\text { logia e Geologia no ensino secundário (16-18 anos de } \\
\text { idade). }\end{array}$ \\
\hline & $\begin{array}{l}\text { 3.3. Apenas uma mínima parte dos minerais co- } \\
\text { nhecidos são constituintes habituais das rochas. }\end{array}$ & $\begin{array}{l}\text { 3.3. Reconhecer a existência de minerais na constituição } \\
\text { das rochas, com base na observação de amostras de mão. } \\
\left(5 .^{\circ} \text { ano) }\right. \\
\text { 2.2. Identificar minerais nas rochas (biotite, calcite, } \\
\text { estaurolite, feldspato, moscovite, olivina, quartzo), } \\
\text { correlacionando algumas propriedades com o uso de } \\
\text { tabelas. ( } 7 .^{\circ} \text { ano) }\end{array}$ \\
\hline & $\begin{array}{l}\text { 3.4. Os minerais são de natureza tão diversa } \\
\text { como variados são os seus usos. }\end{array}$ & $\begin{array}{l}\text { 3. Compreender a importância das rochas e dos } \\
\text { minerais. }\left(5 .^{\circ} \text { ano) }\right. \\
\text { 2. Compreender os minerais como unidades básicas das } \\
\text { rochas. }\left(7 .^{\circ} \text { ano) }\right. \\
\text { 10. Compreender que as formações litológicas em } \\
\text { Portugal devem ser exploradas de forma sustentada. (7. } \\
\text { ano) }\end{array}$ \\
\hline & $\begin{array}{l}\text { 3.5. Os materiais terrestres originam-se e modi- } \\
\text { ficam-se através de processos cíclicos. }\end{array}$ & 9. Conhecer o ciclo das rochas. $\left(7 .^{\circ}\right.$ ano) \\
\hline & $\begin{array}{l}\text { 3.6. As rochas ígneas geram-se no interior da } \\
\text { Terra a temperaturas e pressões elevadas. }\end{array}$ & $\begin{array}{l}\text { 7. Interpretar a formação das rochas magmáticas. ( } 7 .^{\circ} \\
\text { ano) }\end{array}$ \\
\hline & $\begin{array}{l}\text { 3.7. As rochas metamórficas originam-se a par- } \\
\text { tir de outras rochas por ação da temperatura e } \\
\text { da pressão. }\end{array}$ & $\begin{array}{l}\text { 8. Compreender o metamorfismo como uma } \\
\text { consequência da dinâmica interna da Terra. ( } 7 .^{\circ} \text { ano) }\end{array}$ \\
\hline & $\begin{array}{l}\text { 3.8. As rochas que afloram à superfície terrestre } \\
\text { são alteradas por meteorização. }\end{array}$ & \multirow{3}{*}{$\begin{array}{l}\text { 3. Analisar os conceitos e os processos relativos à } \\
\text { formação das rochas sedimentares. ( } 7 .^{\circ} \text { ano) }\end{array}$} \\
\hline & $\begin{array}{l}\text { 3.9. Os sedimentos e as rochas sedimentares } \\
\text { originam-se através do depósito de componen- } \\
\text { tes erodidos de outras rochas. }\end{array}$ & \\
\hline & $\begin{array}{l}\text { 3.10. As rochas sedimentares constituem o } \\
\text { principal arquivo da história geológica e o de- } \\
\text { senvolvimento da vida na Terra. }\end{array}$ & \\
\hline
\end{tabular}

\section{A água e $\mathbf{0}$ ar fazem da Terra um planeta especial}

$\mathrm{Na}$ ideia-chave quatro - $A$ água e o ar fazem da Terra um planeta especial - incluem-se sete sub-ideias, baseando-se na abordagem da Terra como um sistema, com os seus vários subsistemas, que interagem entre si (Tab. 4).

O conhecimento de que a água e o ar fazem parte de sistemas dinâmicos que se foram alterando ao longo da história da Terra, mas que contribuíram para o aparecimento e a evolução da vida no planeta, constituem temas abordados nos $5 .^{\circ}, 7^{\circ} \mathrm{e}$ 8. ${ }^{\circ}$ anos de escolaridade na disciplina de Ciências Naturais (Tab. 4)

\section{A vida evolui e interage com a Terra modificando- se mutuamente}

A ideia-chave cinco - A vida evolui e interage com a Terra modificando-se mutuamente - inclui oito sub-ideias, baseando-se na abordagem da Terra como um sistema, com os seus vários subsistemas, que interagem entre si (Tab. 5).

Da análise da Tab. 5 verifica-se que a disciplina de Ciências Naturais (Ministério da Educação 2013 ) inclui temáticas, lecionadas nos $7 .^{\circ}$ e $8 .^{\circ}$ anos de escolaridade, que permitem que os alunos compreendam que os fósseis se constituem como testemunhos da vida da Terra e que contribuem para 
Tabela 4. Análise sinótica da ideia-chave $A$ água e o ar fazem da Terra um planeta especial e das metas curriculares para a disciplina de Ciências Naturais

\begin{tabular}{|c|c|c|}
\hline \multicolumn{2}{|r|}{$\begin{array}{l}\text { Ideia-chave 4: A água e o ar fazem da Terra um } \\
\text { planeta especial } \\
\text { (Pedrinaci et al. 2013) }\end{array}$} & $\begin{array}{l}\text { Metas curriculares de Ciências Naturais }{ }^{1} \\
\text { (Ministério da Educação 2013) }\end{array}$ \\
\hline \multirow{11}{*}{ 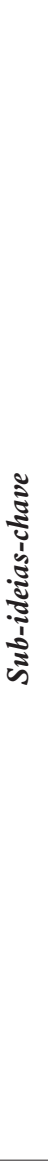 } & $\begin{array}{l}\text { 4.1. A Terra apresenta duas camadas flui- } \\
\text { das: a hidrosfera e a atmosfera. }\end{array}$ & \multirow{5}{*}{$\begin{array}{l}\text { 4. Compreender a importância da água para os seres vivos. }\left(5 .^{\circ}\right. \\
\text { ano) } \\
\text { 5. Compreender a importância da qualidade da água para a } \\
\text { atividade humana. }\left(5 .^{\circ} \text { ano) }\right. \\
\text { 6. Compreender a importância da atmosfera para os seres vivos. } \\
\left(5 .^{\circ} \text { ano) }\right. \\
\text { 1. Compreender as condições próprias da Terra que a tornam o } \\
\text { único planeta com vida conhecida no Sistema Solar. }\left(8 .^{\circ} \text { ano) }\right.\end{array}$} \\
\hline & $\begin{array}{l}\text { 4.2. A Terra é um planeta singular devido à } \\
\text { presença de água. }\end{array}$ & \\
\hline & $\begin{array}{l}\text { 4.3. A água está presente na Terra nos seus } \\
\text { três estados físicos. }\end{array}$ & \\
\hline & $\begin{array}{l}\text { 4.4. A atmosfera alterou significativamente } \\
\text { a sua composição química ao longo da } \\
\text { história do planeta. }\end{array}$ & \\
\hline & $\begin{array}{l}\text { 4.5. A composição e a estrutura da atmos- } \\
\text { fera determinam algumas características } \\
\text { fundamentais da Terra. }\end{array}$ & \\
\hline & \multirow{3}{*}{$\begin{array}{l}\text { 4.6. A hidrosfera e a atmosfera são sistemas } \\
\text { dinâmicos. }\end{array}$} & $\begin{array}{l}\text { 14.7. Inferir as consequências das mudanças cíclicas dos } \\
\text { subsistemas terrestres (atmosfera, biosfera, geosfera, hidrosfera) } \\
\text { ao longo da história da Terra, com base em documentos } \\
\text { diversificados. ( } 7 .^{\circ} \text { ano) }\end{array}$ \\
\hline & & $\begin{array}{l}\text { 1.4. Descrever a influência da atividade dos seres vivos na } \\
\text { evolução da atmosfera terrestre. }\left(8^{\circ} \text { ano) }\right.\end{array}$ \\
\hline & & $\begin{array}{l}\text { 8. Sintetizar o papel dos principais ciclos de matéria nos } \\
\text { ecossistemas. ( } 8 .^{\circ} \text { ano) }\end{array}$ \\
\hline & \multirow{3}{*}{$\begin{array}{l}\text { 4.7. Os climas variaram ao longo da histó- } \\
\text { ria da Terra. }\end{array}$} & $\begin{array}{l}\text { 1.3. Interpretar gráficos da evolução da temperatura, da energia } \\
\text { solar e do dióxido de carbono atmosférico ao longo do tempo } \\
\text { geológico. ( } 8 .^{\circ} \text { ano) }\end{array}$ \\
\hline & & $\begin{array}{l}\text { 1.5. Inferir a importância do efeito de estufa para a manutenção } \\
\text { de uma temperatura favorável à vida na Terra. }\left(8 .^{\circ} \text { ano }\right)\end{array}$ \\
\hline & & $\begin{array}{l}\text { 15.1. Associar as intervenções do ser humano aos impactes nos } \\
\text { processos geológicos (atmosfera, hidrosfera e litosfera). ( } 7 .^{\circ} \\
\text { ano) }\end{array}$ \\
\hline
\end{tabular}

a compreensão da diversidade de seres vivos existentes na Terra, em diferentes momentos da sua história, bem como os principais acontecimentos que poderão ter contribuído para algumas extinções em massa e o modo como ocorreu a sua evolução. Deste modo, através da abordagem destas temáticas os alunos poderão ser sensibilizados para o modo como a vida evoluiu ao longo do tempo e o modo como as interações com o planeta Terra são recíprocas e das consequências que daí advieram para ambos.

\section{A tectónica de placas é uma teoria global e integradora da Terra}

A ideia-chave seis - A tectónica de placas é uma teoria global e integradora da Terra - inclui oito sub-ideias, baseando-se na abordagem da Terra como um sistema, com os seus vários subsistemas, que interagem entre si (Tab. 6).
Ao nível do $7 .^{\circ}$ ano de escolaridade (Tab. 6) são explorados temas que permitem a perceção das dinâmicas do planeta Terra e do modo como evoluiu o conhecimento científico nesta área, bem como os contributos que a tecnologia deu para a compreensão da Tectónica de Placas. Também são estudadas as consequências que advêm da dinâmica do planeta Terra para a formação do relevo terrestre e as consequências da mesma na distribuição e ocorrência de sismos e de vulcões.

\section{Os processos geológicos externos transformam a superfície terrestre}

A ideia-chave sete - Os processos geológicos externos transformam a superficie terrestre - inclui nove sub-ideias, baseando-se na abordagem da Terra como um sistema, com os seus vários subsistemas, que interagem entre si (Tab. 7). 
Tabela 5. Análise sinótica da ideia-chave $A$ vida evolui e interage com a Terra modificando-se mutuamente e das metas curriculares para a disciplina de Ciências Naturais

\begin{tabular}{|c|c|c|}
\hline \multicolumn{2}{|r|}{$\begin{array}{c}\text { Ideia-chave 5: A vida evolui e interage com a Terra } \\
\text { modificando-se mutuamente }\end{array}$} & $\begin{array}{l}\text { Metas curriculares de Ciências Naturais }{ }^{1} \\
\text { (Ministério da Educação 2013) }\end{array}$ \\
\hline \multirow{8}{*}{ 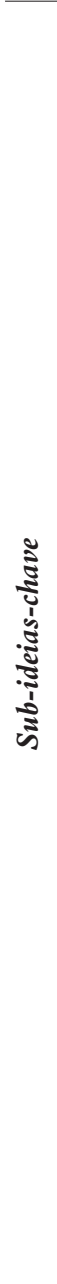 } & $\begin{array}{l}\text { 5.1. Os fósseis constituem o testemunho da vida } \\
\text { no passado e ajudam a entender o presente. }\end{array}$ & $\begin{array}{l}\text { 13. Compreender a importância dos fósseis para a } \\
\text { reconstituição da história da Terra. }\left(7 .^{\circ} \text { ano }\right)\end{array}$ \\
\hline & $\begin{array}{l}\text { 5.2. A origem e evolução da vida estão ligadas à } \\
\text { própria evolução da Terra como planeta. }\end{array}$ & $\begin{array}{l}\text { 1.2. Explicar três condições da Terra que permitiram o } \\
\text { desenvolvimento e a manutenção da vida. }\left(8 .^{\circ} \text { ano) }\right. \\
\text { 2.3. Argumentar sobre algumas teorias da origem da vida } \\
\text { na Terra. }\left(8^{\circ}{ }^{\circ} \text { ano }\right) \\
\text { 2.4. Discutir o papel da alteração das rochas e da } \\
\text { formação do solo na existência de vida no meio terrestre. } \\
\text { (8. }{ }^{\circ} \text { ano) } \\
\text { 2.5. Justificar o papel dos subsistemas na manutenção da } \\
\text { vida na Terra. }\left(8 .^{\circ} \text { ano) }\right.\end{array}$ \\
\hline & 5.3. A diversidade biológica surge da evolução. & $\begin{array}{l}\text { 1. Compreender as condições próprias da Terra que a } \\
\text { tornam o único planeta com vida conhecida no Sistema } \\
\text { Solar. ( } 8 .^{\circ} \text { ano) } \\
\text { 14.7. Inferir as consequências das mudanças cíclicas dos } \\
\text { subsistemas terrestres (atmosfera, biosfera, geosfera, } \\
\text { hidrosfera) ao longo da história da Terra, com base em } \\
\text { documentos diversificados. ( } 7 .^{\circ} \text { ano) }\end{array}$ \\
\hline & $\begin{array}{l}\text { 5.4. A evolução é um processo natural e em } \\
\text { desenvolvimento marcado por acontecimentos } \\
\text { geológicos. }\end{array}$ & $\begin{array}{l}\text { 14.8. Caraterizar ambientes geológicos passados, através } \\
\text { de uma atividade prática de campo. }\left(7 .^{\circ} \text { ano }\right)\end{array}$ \\
\hline & $\begin{array}{l}\text { 5.5. A história da Terra está marcada por impor- } \\
\text { tantes eventos de extinção e diversificação dos } \\
\text { seres vivos. }\end{array}$ & \multirow{2}{*}{$\begin{array}{l}\text { 14.6. Localizar o aparecimento e a extinção dos } \\
\text { principais grupos de animais e de plantas na Tabela } \\
\text { Cronostratigráfica. ( } 7 .^{\circ} \text { ano) }\end{array}$} \\
\hline & $\begin{array}{l}\text { 5.6. As particulares formas de vida que existem } \\
\text { atualmente, incluindo a espécie humana, são um } \\
\text { resultado único da história de Terra. }\end{array}$ & \\
\hline & $\begin{array}{l}\text { 5.7. A vida ocupa um amplo espetro de ambientes } \\
\text { da Terra, incluindo os ambientes extremos. }\end{array}$ & $\begin{array}{l}\text { 5. Analisar as dinâmicas de interação existentes entre os } \\
\text { seres vivos e o ambiente. }\left(8 .^{\circ} \text { ano) }\right.\end{array}$ \\
\hline & 5.8. A biosfera muda as propriedades da Terra. & $\begin{array}{l}\text { 1.4. Descrever a influência da atividade dos seres vivos } \\
\text { na evolução da atmosfera terrestre. }\left(8 .^{\circ} \text { ano }\right)\end{array}$ \\
\hline
\end{tabular}

Pela análise da Tab. 7 contata-se que na lecionação da disciplina de Ciências Naturais (Ministério da Educação 2013), ao nível do 7. ${ }^{\circ}$ ano de escolaridade, são estudadas temáticas que permitem que os alunos compreendam o modo como os processos geológicos externos, onde também se incluem os seres vivos, modificam a superfície terrestre e condicionam a sua morfologia.

\section{A humanidade depende do planeta Terra para a obtenção dos seus recursos e deve fazê-lo de modo sustentável}

A ideia-chave oito - A humanidade depende do planeta Terra para a obtenção dos seus recursos e deve fazê-lo de modo sustentável - inclui oito sub-ideias, baseando-se na abordagem da Terra como um siste-

ma, com os seus vários subsistemas, que interagem entre si (Tab. 8).

Ao nível dos 7. ${ }^{\circ}$ e $8 .^{\circ}$ anos de escolaridade, os alunos compreendam que a humanidade tem investido muito na extração de imensos recursos naturais geológicos e de recursos naturais energéticos do planeta Terra e que utiliza para promover o desenvolvimento das sociedades (Tab. 8). Os alunos são sensibilizados para a necessidade de promover a exploração sustentada destes recursos se queremos que eles continuem a ser utilizados pelas gerações futuras.

\section{Alguns processos naturais implicam riscos para a humanidade}

A ideia-chave nove - Alguns processos naturais implicam riscos para a humanidade - inclui sete sub- 
Tabela 6.Análise sinótica da ideia-chave A tectónica de placas é uma teoria global e integradora da Terra e das metas curriculares para a disciplina de Ciências Naturais

\begin{tabular}{|c|c|c|}
\hline \multicolumn{2}{|c|}{$\begin{array}{l}\text { Ideia-chave 6: A tectónica de placas é uma } \\
\text { teoria global e integradora da Terra } \\
\text { (Pedrinaci et al. 2013) }\end{array}$} & $\begin{array}{l}\text { Metas curriculares de Ciências Naturais }{ }^{1} \\
\text { (Ministério da Educação 2013) }\end{array}$ \\
\hline \multirow{7}{*}{ 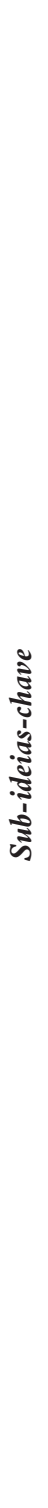 } & $\begin{array}{l}\text { 6.1. A Terra funciona como uma } \\
\text { enorme máquina térmica que não } \\
\text { deixou de arrefecer desde que se } \\
\text { formou. }\end{array}$ & $\begin{array}{l}\text { 4.7. Identificar os contributos de alguns cientistas associados à Teoria } \\
\text { da Deriva Continental e à Teoria da Tectónica de Placas. ( } 7 .^{\circ} \text { ano) } \\
\text { 4.9. Inferir a importância das correntes de convecção como "motor" da } \\
\text { mobilidade das placas tectónicas. }\left(7 .^{\circ} \text { ano) }\right.\end{array}$ \\
\hline & $\begin{array}{l}\text { 6.3. O movimento do material no } \\
\text { interior da Terra gera um campo } \\
\text { magnético. }\end{array}$ & $\begin{array}{l}\text { 4.6. Resolver um exercício que relacione a distância ao eixo da dorsal } \\
\text { atlântica com a idade e o paleomagnetismo das rochas do respetivo } \\
\text { fundo oceânico. ( } 7 .^{\circ} \text { ano) }\end{array}$ \\
\hline & $\begin{array}{l}\text { 6.4. A atividade interna da Terra é } \\
\text { responsável pela tectónica de placas. }\end{array}$ & $\begin{array}{l}\text { 4.4. Explicar as evidências clássicas (oceânicas e continentais) que } \\
\text { fundamentam a Teoria da Tectónica de Placas. }\left(7 .^{\circ} \text { ano) }\right. \\
\text { 4.9. Inferir a importância das correntes de convecção como "motor" da } \\
\text { mobilidade das placas tectónicas. }\left(7 .^{\circ} \text { ano) }\right.\end{array}$ \\
\hline & $\begin{array}{l}\text { 6.5. A litosfera encontra-se dividida } \\
\text { em placas que estão em contínuo } \\
\text { movimento. }\end{array}$ & $\begin{array}{l}\text { 4.1. Apresentar argumentos que apoiaram e fragilizaram a Teoria da } \\
\text { Deriva Continental. ( } 7 .^{\circ} \text { ano) } \\
\text { 4.2. Reconhecer o contributo da ciência, da tecnologia e da sociedade } \\
\text { para o conhecimento da expansão dos fundos oceânicos. }\left(7 .^{\circ} \text { ano) }\right. \\
\text { 4.3. Esquematizar a morfologia dos fundos oceânicos }\left(7 .^{\circ} \text { ano) }\right. \\
\text { 4.4. Explicar as evidências clássicas (oceânicas e continentais) que } \\
\text { fundamentam a Teoria da Tectónica de Placas. ( } 7 .^{\circ} \text { ano) } \\
\text { 4.5. Relacionar a expansão e a destruição contínuas dos fundos } \\
\text { oceânicos com a constância do volume da Terra. }\left(7 .^{\circ} \text { ano) }\right.\end{array}$ \\
\hline & $\begin{array}{l}\text { 6.6. O movimento das placas defor- } \\
\text { ma as rochas da crusta terrestre. }\end{array}$ & 5. Aplicar conceitos relativos à deformação das rochas. $\left(7 .^{\circ}\right.$ ano $)$ \\
\hline & $\begin{array}{l}\text { 6.7. Os bordos das placas são zonas } \\
\text { de maior atividade geológica. }\end{array}$ & $\begin{array}{l}\text { 4.8. Caraterizar placa tectónica e os diferentes tipos de limites } \\
\text { existentes. }\left(7 .^{\circ} \text { ano) }\right. \\
\text { 11.11. Relacionar a distribuição dos sismos e dos vulcões na Terra com } \\
\text { os diferentes limites de placas tectónicas. }\left(7 .^{\circ} \text { ano) }\right.\end{array}$ \\
\hline & $\begin{array}{l}\text { 6.8. A ação conjunta do movimento } \\
\text { das placas litosféricas, a gravidade e } \\
\text { o fluxo térmico controlam os gran- } \\
\text { des elementos do relevo terrestre. }\end{array}$ & 5. Aplicar conceitos relativos à deformação das rochas. ( $7 .^{\circ}$ ano) \\
\hline
\end{tabular}

-ideias, baseando-se na abordagem da Terra como um sistema, com os seus vários subsistemas, que interagem entre si (Tab. 9).

Decorrente da análise da Tab. 9 constata-se que na lecionação da disciplina de Ciências Naturais (Ministério da Educação 2013) são abordadas temáticas, em diferentes anos de escolaridade (7..$^{\circ}$ e $8 .^{\circ}$ anos), que permitem que os alunos conheçam riscos que advêm de alguns processos naturais e das medidas que podem ser tomadas para os minimizar.

\section{Os cientistas interpretam e explicam 0 funcionamento da Terra baseando-se em observações repetíveis e em ideias verificáveis}

A ideia-chave dez - Os cientistas interpretam e explicam o funcionamento da Terra baseando-se em observações repetíveis e em ideias verificáveis - inclui seis sub-ideias, baseando-se na abordagem da Terra como um sistema, com os seus vários subsistemas, que interagem entre si (Tab. 10).

Ao nível do $7 .^{\circ}$ ano de escolaridade (Tab. 10) 
Tabela 7. Análise sinótica da ideia-chave Os processos geológicos externos transformam a superfície terrestre e das metas curriculares para a disciplina de Ciências Naturais

\begin{tabular}{|c|c|c|}
\hline \multicolumn{2}{|r|}{$\begin{array}{l}\text { Ideia-chave 7: Os processos geológicos externos trans- } \\
\text { formam a superfície terrestre } \\
\text { (Pedrinaci et al. 2013) }\end{array}$} & $\begin{array}{l}\text { Metas curriculares de Ciências Naturais } \\
\text { (Ministério da Educação 2013) }\end{array}$ \\
\hline \multirow{10}{*}{ 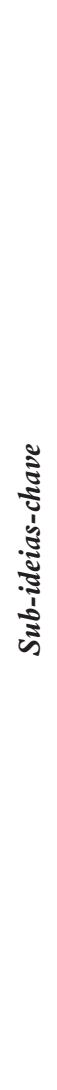 } & $\begin{array}{l}\text { 7.1. Os processos externos modelam o relevo e } \\
\text { evidenciam o dinamismo superficial do planeta. }\end{array}$ & $\begin{array}{l}\text { 3.1. Resumir a ação da água, do vento e dos seres vivos } \\
\left.\text { enquanto agentes geológicos externos. ( } 7 .^{\circ} \text { ano }\right)\end{array}$ \\
\hline & $\begin{array}{l}\text { 7.2. Os agentes e os fluxos de energia são os } \\
\text { causadores da dinâmica externa do planeta. }\end{array}$ & $\begin{array}{l}\text { 3.2. Prever o tipo de deslocação e de deposição de } \\
\text { materiais ao longo de um curso de água, com base numa } \\
\text { atividade prática laboratorial. ( } 7 .^{\circ} \text { ano) }\end{array}$ \\
\hline & $\begin{array}{l}\text { 7.3. O campo gravítico terrestre faz com que os } \\
\text { materiais tendam a deslocar-se desde posições } \\
\text { elevadas para outras mais baixas. }\end{array}$ & $\begin{array}{l}\text { 3.2. Prever o tipo de deslocação e de deposição de mate- } \\
\text { riais ao longo de um curso de água, com base numa ativi- } \\
\text { dade prática laboratorial. ( } 7 .^{\circ} \text { ano) }\end{array}$ \\
\hline & $\begin{array}{l}\text { 7.4. As águas que circulam por zonas conti- } \\
\text { nentais erodem, transportam e sedimentam } \\
\text { materiais. }\end{array}$ & \multirow{3}{*}{$\begin{array}{l}\text { 3.1. Resumir a ação da água, do vento e dos seres vivos } \\
\text { enquanto agentes geológicos externos. ( } 7 .^{\circ} \text { ano) } \\
\text { 3.2. Prever o tipo de deslocação e de deposição de mate- } \\
\text { riais ao longo de um curso de água, com base numa ativi- } \\
\text { dade prática laboratorial. ( } 7 .^{\circ} \text { ano) }\end{array}$} \\
\hline & $\begin{array}{l}\text { 7.5. A ação geológica das águas marinhas mani- } \\
\text { festa-se, principalmente, nas zonas litorais. }\end{array}$ & \\
\hline & $\begin{array}{l}\text { 7.6. Os glaciares cobrem quase } 10 \% \text { da superfí- } \\
\text { cie terrestre. }\end{array}$ & \\
\hline & \multirow{2}{*}{$\begin{array}{l}\text { 7.7. Os processos eólicos têm um papel impor- } \\
\text { tante nos ambientes áridos do planeta. }\end{array}$} & $\begin{array}{l}\text { 3.1. Resumir a ação da água, do vento e dos seres vivos } \\
\text { enquanto agentes geológicos externos. ( } 7 .^{\circ} \text { ano) }\end{array}$ \\
\hline & & $\begin{array}{l}\text { 3.6. Associar algumas caraterísticas das areias a diferentes } \\
\text { tipos de ambientes, com base numa atividade prática } \\
\text { laboratorial. ( } 7 .^{\circ} \text { ano) }\end{array}$ \\
\hline & $\begin{array}{l}\text { 7.8. Os seres vivos também exercem uma ativi- } \\
\text { dade geológica. }\end{array}$ & \multirow{2}{*}{$\begin{array}{l}\text { 3.1. Resumir a ação da água, do vento e dos seres vivos } \\
\text { enquanto agentes geológicos externos. }\left(7 .^{\circ} \text { ano }\right)\end{array}$} \\
\hline & $\begin{array}{l}\text { 7.9. A espécie humana é um agente ativo que } \\
\text { transforma a superfície terrestre. }\end{array}$ & \\
\hline
\end{tabular}

são transversalmente abordadas temáticas que permitem que os alunos compreendam que os cientistas interpretam e explicam o funcionamento do planeta Terra baseando-se em observações repetíveis e em ideias verificáveis e, deste modo, dão um contributo importante para o conhecimento do planeta Terra.

Da análise sinótica anterior pode perceber-se que as metas curriculares da disciplina de Ciências Naturais têm uma correspondência superior a 96\% com as ideias-chave da comissão ad hoc espanhola. Fica de fora da disciplina de Ciências Naturais o estudo da origem do Sistema Solar - sub-ideia 2.2. - e o dos processos de formação da Terra, há cerca de $4.600 \mathrm{Ma}$, mediante múltiplas colisões de corpos planetários mais pequenos (sub-ideia 2.3.), que se opera na disciplina de Ciências Físico-Químicas no ensino básico.

A sub-ideia 3.2. - "Os elementos químicos mais abundantes nas rochas e nos minerais da crusta ter- restre são o oxigénio, o silício e o alumínio" - está ausente do ensino básico, vindo a ser estudada na disciplina de Biologia e Geologia do ensino secundário (16-18 anos de idade).

As metas curriculares, tal como foram concebidas as próprias ideias-chave, devem constituir-se como "um documento vivo que cresce junto com os conhecimentos cada vez mais ajustados que os geólogos e os demais cientistas têm sobre a Terra, e que se associa com a solicitação de uma sociedade cada dia mais globalizada e interdependente (Pedrinaci et al. 2013:129). A sua operacionalização, por meio de práticas letivas fundamentadas no atual conhecimento didático e neuroeducativo, traduzidas nas principais ideias estruturantes do ensino das ciências - i) Ensino em contexto, ii) Centralidade dos alunos na aprendizagem e a mediação do professor, iii) Trabalho prático; iv) Relação Ciência-Tecnologia-Sociedade-Ambiente; v) Compreensão da natureza da Ciência (Rebelo 
Tabela 8.Análise sinótica da ideia-chave "A humanidade depende do planeta Terra para a obtenção dos seus recursos e deve fazê-lo de modo sustentável" e das metas curriculares para a disciplina de Ciências Naturais

\begin{tabular}{|c|c|c|}
\hline \multicolumn{2}{|c|}{$\begin{array}{l}\text { Ideia-chave 8: A humanidade depende do } \\
\text { planeta Terra para a obtenção dos seus re- } \\
\text { cursos e deve fazê-lo de modo sustentável } \\
\text { (Pedrinaci et al. 2013) }\end{array}$} & $\begin{array}{l}\text { Metas curriculares de Ciências Naturais }{ }^{1} \\
\text { (Ministério da Educação 2013) }\end{array}$ \\
\hline \multirow{8}{*}{ 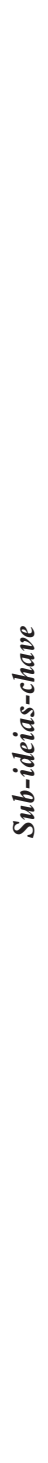 } & $\begin{array}{l}\text { 8.1. A Terra é o nosso lar, dela obte- } \\
\text { mos todos os recursos que utiliza- } \\
\text { mos e a ela devolvemos os resíduos } \\
\text { gerados. }\end{array}$ & $\begin{array}{l}\text { 14. Compreender o modo como são explorados e transformados os } \\
\text { recursos naturais. }\left(8 .^{\circ} \text { ano) }\right. \\
\text { 17. Relacionar a gestão de resíduos e da água com o desenvolvimento } \\
\text { sustentável. }\left(8 .^{\circ} \text { ano) }\right.\end{array}$ \\
\hline & $\begin{array}{l}\text { 8.2. A geologia afeta a distribuição e } \\
\text { o desenvolvimento das populações } \\
\text { humanas. }\end{array}$ & $\begin{array}{l}\text { 6.5. Explicar os benefícios do vulcanismo (principal e secundário) para } \\
\text { as populações. ( } 7 .^{\circ} \text { ano) }\end{array}$ \\
\hline & $\begin{array}{l}\text { 8.3. Os recursos naturais geológicos } \\
\text { são limitados. }\end{array}$ & $\begin{array}{l}\text { 15.3. Extrapolar o impacte do crescimento populacional no consumo } \\
\text { de recursos, no ambiente e na sustentabilidade da vida na Terra. ( } 7 .^{\circ} \\
\text { ano) } \\
\text { 13. Compreender a classificação dos recursos naturais. }\left(8 .^{\circ} \text { ano) }\right. \\
\text { 14. Compreender o modo como são explorados e transformados os } \\
\text { recursos naturais. }\left(8 .^{\circ} \text { ano) }\right.\end{array}$ \\
\hline & $\begin{array}{l}\text { 8.4. O solo é essencial para diversos } \\
\text { organismos e para a humanidade, } \\
\text { constituindo o sustento da agricul- } \\
\text { tura. }\end{array}$ & $\begin{array}{l}\text { 2. Compreender que o solo é um material terrestre de suporte de vida. } \\
\left(5 .^{\circ} \text { ano) }\right. \\
\text { 2.4. Discutir o papel da alteração das rochas e da formação do solo na } \\
\text { existência de vida no meio terrestre. }\left(8 .^{\circ} \text { ano }\right)\end{array}$ \\
\hline & $\begin{array}{l}\text { 8.5. As rochas e os minerais propor- } \\
\text { cionam os metais e outros materiais } \\
\text { essenciais para muitas atividades } \\
\text { industriais. }\end{array}$ & $\begin{array}{l}\text { 3.4. Referir aplicações das rochas e dos minerais em diversas atividades } \\
\text { humanas, com base numa atividade prática de campo na região onde a } \\
\text { escola se localiza. ( } 5 .^{\circ} \text { ano) } \\
\text { 10. Compreender que as formações litológicas em Portugal devem ser } \\
\text { exploradas de forma sustentada. }\left(7 .^{\circ} \text { ano) }\right.\end{array}$ \\
\hline & $\begin{array}{l}\text { 8.6. Os combustíveis fósseis são } \\
\text { recursos energéticos essenciais e } \\
\text { deles se obtêm numerosos produtos } \\
\text { de uso quotidiano. }\end{array}$ & \multirow{2}{*}{$\begin{array}{l}\text { 13. Compreender a classificação dos recursos naturais. }\left(8 .^{\circ} \text { ano) }\right. \\
\text { 14. Compreender o modo como são explorados e transformados os } \\
\text { recursos naturais. }\left(8 .^{\circ} \text { ano) }\right.\end{array}$} \\
\hline & $\begin{array}{l}\text { 8.7. Os geólogos, engenheiros e } \\
\text { outros cientistas desenvolvem novas } \\
\text { tecnologias que reduzem os efeitos } \\
\text { da extração e proporcionam novos } \\
\text { recursos. }\end{array}$ & \\
\hline & $\begin{array}{l}\text { 8.8. A singular história de cada um } \\
\text { dos lugares da Terra proporciona, } \\
\text { além disso, uma imensa variedade } \\
\text { de manifestações geológicas. }\end{array}$ & $\begin{array}{l}\text { 6.4. Exemplificar manifestações de vulcanismo secundário. }\left(7 .^{\circ} \text { ano) }\right. \\
\text { 6.5. Explicar os benefícios do vulcanismo (principal e secundário) para } \\
\text { as populações. ( } 7 .^{\circ} \text { ano) }\end{array}$ \\
\hline
\end{tabular}

et al. 2017) - permitirá que os alunos tenham uma visão holística de como funciona a Terra e capacidade para utilizar esse conhecimento básico para explicar vários fenómenos. Além disso, ficarão municiados de uma certa perspetiva temporal sobre as profundas alterações que afetaram o nosso planeta, compreendendo melhor a necessidade da gestão de recursos de modo sustentável para garantir condições adequadas de vida às gerações futuras, sendo capazes de pesquisar e selecionar informação relevante sobre alguns dos processos e fenómenos que ocorrem na Terra e entender algumas das principais interações entre a Humanidade e a sua única casa - o planeta Terra.

\section{Considerações finais}

A definição das metas curriculares veio introduzir, explicitamente, os conteúdos fundamentais que devem ser ensinados e a ordenação sequencial ou hierárquica dos mesmos, os conhecimentos e as capacidades a adquirir e a desenvolver pelos alunos e 
Tabela 9.Análise sinótica da ideia-chave Alguns processos naturais implicam riscos para a humanidade e das metas curriculares para a disciplina de Ciências Naturais

\begin{tabular}{|c|c|c|}
\hline \multicolumn{2}{|r|}{$\begin{array}{l}\text { Ideia-chave 9: Alguns processos naturais im- } \\
\text { plicam riscos para a humanidade } \\
\text { (Pedrinaci et al. 2013) }\end{array}$} & $\begin{array}{c}\text { Metas curriculares de Ciências Naturais }{ }^{1} \\
\text { (Ministério da Educação 2013) }\end{array}$ \\
\hline \multirow{7}{*}{ 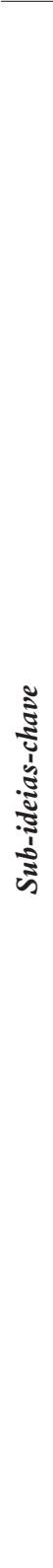 } & $\begin{array}{l}\text { 9.1. Os riscos naturais são consequência } \\
\text { de certos processos naturais. }\end{array}$ & $\begin{array}{l}\text { 6. Compreender a atividade vulcânica como uma manifestação } \\
\text { da dinâmica interna da Terra. }\left(7 .^{\circ} \text { ano) }\right. \\
\text { 11. Compreender a atividade sísmica como uma consequência da } \\
\text { dinâmica interna da Terra. }\left(7 .^{\circ} \text { ano) }\right.\end{array}$ \\
\hline & $\begin{array}{l}\text { 9.2. A afetação dos riscos à humanidade } \\
\text { é determinada pela perigosidade, a ex- } \\
\text { posição e a vulnerabilidade. }\end{array}$ & $\begin{array}{l}\text { 15.1. Associar as intervenções do ser humano aos impactes nos } \\
\text { processos geológicos (atmosfera, hidrosfera e litosfera). }\left(7 .^{\circ} \text { ano) }\right. \\
\text { 15.2. Relacionar o ambiente geológico com a saúde e a } \\
\text { ocorrência de doenças nas pessoas, nos animais e nas plantas que } \\
\text { vivem nesse mesmo ambiente. }\left(7 .^{\circ} \text { ano) }\right. \\
\text { 15. Relacionar o papel dos instrumentos de ordenamento e } \\
\text { gestão do território com a proteção e a conservação da Natureza. } \\
\left(8 .^{\circ} \text { ano) }\right.\end{array}$ \\
\hline & $\begin{array}{l}\text { 9.3. A perigosidade pode dever-se tanto } \\
\text { a eventos repentinos como graduais. }\end{array}$ & $\begin{array}{l}\text { 3.1. Resumir a ação da água, do vento e dos seres vivos enquanto } \\
\text { agentes geológicos externos. ( } 7 .^{\circ} \text { ano) } \\
\text { 6. Compreender a atividade vulcânica como uma manifestação } \\
\text { da dinâmica interna da Terra. }\left(7 .^{\circ} \text { ano) }\right. \\
\text { 11. Compreender a atividade sísmica como uma consequência da } \\
\text { dinâmica interna da Terra. }\left(7 .^{\circ} \text { ano) }\right.\end{array}$ \\
\hline & $\begin{array}{l}\text { 9.4. Os eventos locais podem ter reper- } \\
\text { cussões globais. }\end{array}$ & $\begin{array}{l}\text { 6. Compreender a atividade vulcânica como uma manifestação } \\
\text { da dinâmica interna da Terra. ( } 7 .^{\circ} \text { ano) }\end{array}$ \\
\hline & $\begin{array}{l}\text { 9.5. Os cientistas melhoram as estima- } \\
\text { tivas acerca de onde, por quê e em que } \\
\text { medida existem riscos naturais. }\end{array}$ & $\begin{array}{l}\text { 6.7. Inferir a importância da ciência e da tecnologia na previsão } \\
\text { de erupções vulcânicas. ( } 7 .^{\circ} \text { ano) } \\
\text { 11.10. Reconhecer a importância da ciência e da tecnologia na } \\
\text { previsão sísmica. ( } 7 .^{\circ} \text { ano) } \\
\text { 15.4. Referir três tipos de respostas (tecnológicas, } \\
\text { socioeconómicas e educativas) a problemas de geologia } \\
\text { ambiental. ( } 7 .^{\circ} \text { ano) }\end{array}$ \\
\hline & $\begin{array}{l}\text { 9.6. As pessoas não podem eliminar } \\
\text { os processos naturais perigosos, mas } \\
\text { podem adotar decisões que reduzam o } \\
\text { risco. }\end{array}$ & $\begin{array}{l}\text { 6.6. Referir medidas de prevenção e de proteção de bens e de } \\
\text { pessoas do risco vulcânico. }\left(7 .^{\circ} \text { ano }\right) \\
\text { 11.9. Descrever medidas de proteção de bens e de pessoas, antes, } \\
\text { durante e após a ocorrência de um sismo. }\left(7 .^{\circ} \text { ano }\right)\end{array}$ \\
\hline & $\begin{array}{l}\text { 9.7. Uma sociedade alfabetizada em Ci- } \\
\text { ências da Terra é essencial para reduzir } \\
\text { drasticamente os riscos naturais. }\end{array}$ & $\begin{array}{l}\text { 15. Compreender o contributo do conhecimento geológico para } \\
\text { a sustentabilidade da vida na Terra. }\left(7 .^{\circ} \text { ano) }\right. \\
\text { 18. Relacionar o desenvolvimento científico e tecnológico com a } \\
\text { melhoria da qualidade de vida das populações humanas. ( } 8 .^{\circ} \text { ano) }\end{array}$ \\
\hline
\end{tabular}

os padrões / níveis de desempenho que se esperam.

As metas curriculares do $5 .^{\circ}(10-11$ anos de idade), $7^{\circ}$ (12-13 anos de idade) e $8 .^{\circ}$ anos (1314 anos de idade) de escolaridade contemplam conteúdos relativos às Ciências da Terra. A análise sinótica elaborada entre estas e as ideias-chave sobre a literacia científica em Ciências da Terra do aluno que completa a escolaridade obrigatória, da comissão ad hoc espanhola criada para o efeito, permite perceber uma correspondência total (com exceção da sub-ideia 3.2), colocando o ensino das Ciências Naturais em Portugal entre a vanguarda dos sistemas educativos que se preocupam e dedicam atenção ao ensino das Ciências da Terra.

A implementação efetiva das metas curriculares de Ciências Naturais acontece sob a orientação dos professores, que são, sem dúvida, os importantes agentes da mudança na sociedade. A definição das 
Tabela 10. Análise sinótica da ideia-chave Os cientistas interpretam e explicam o funcionamento da Terra baseando-se em observações repetíveis e em ideias verificáveis e das metas curriculares para a disciplina de Ciências Naturais

\begin{tabular}{|c|c|c|}
\hline \multicolumn{2}{|c|}{$\begin{array}{l}\text { Ideia-chave 10: Os cientistas interpretam e explicam o } \\
\text { funcionamento da Terra baseando-se em observações } \\
\text { repetíveis e em ideias verificáveis } \\
\text { (Pedrinaci et al. 2013) }\end{array}$} & Metas curriculares de Ciências Naturais ${ }^{1}$ \\
\hline \multirow{6}{*}{ 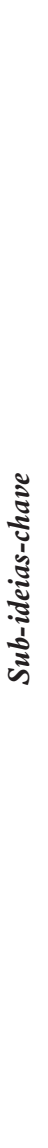 } & $\begin{array}{l}\text { 10.1. Os cientistas utilizam teorias, leis e prin- } \\
\text { cípios de diversas disciplinas para compreender } \\
\text { como funciona o nosso planeta. }\end{array}$ & $\begin{array}{l}\text { 12.3. Explicar os contributos da planetologia, da } \\
\text { sismologia e da vulcanologia para o conhecimento do } \\
\text { interior da Terra. (7. } .^{\circ} \text { ano) } \\
\text { 15.5.Explicar o modo como as relações entre a geologia, } \\
\text { a tecnologia e a sociedade podem contribuir para a } \\
\text { formação de uma cultura de sustentabilidade da vida na } \\
\text { Terra. ( } 7 .^{\circ} \text { ano) }\end{array}$ \\
\hline & $\begin{array}{l}\text { 10.2. As investigações em Ciências da Terra } \\
\text { requerem uma grande variedade de procedi- } \\
\text { mentos. }\end{array}$ & $\begin{array}{l}\text { 12.1. Relacionar a inacessibilidade do interior da Terra } \\
\text { com as limitações dos métodos diretos. ( } 7 .^{\circ} \text { ano) } \\
\begin{array}{l}\text { 12.2. Enumerar diversos instrumentos tecnológicos que } \\
\text { permitem compreender a estrutura interna da Terra. ( } 7 .^{\circ} \\
\text { ano) }\end{array}\end{array}$ \\
\hline & $\begin{array}{l}\text { 10.3. O trabalho de campo é uma ferramenta } \\
\text { básica para abordar a maioria das investigações } \\
\text { ou estudos em Ciências da Terra. }\end{array}$ & $\begin{array}{l}\text { 14.8. Caraterizar ambientes geológicos passados, através } \\
\text { de uma atividade prática de campo. }\left(7 .^{\circ} \text { ano }\right)\end{array}$ \\
\hline & $\begin{array}{l}\text { 10.4. Os geólogos utilizam métodos indiretos } \\
\text { para examinar e compreender a estrutura, com- } \\
\text { posição e dinâmica do interior terrestre. }\end{array}$ & $\begin{array}{l}\text { 12.3. Explicar os contributos da planetologia, da sismo- } \\
\text { logia e da vulcanologia para o conhecimento do interior } \\
\text { da Terra. ( } 7 .^{\circ} \text { ano) } \\
\text { 12.4.Caraterizar, a partir de esquemas, a estrutura interna } \\
\text { da Terra, com base nas propriedades físicas e químicas } \\
\text { (modelo geoquímico e modelo geofísico). }\left(7 .^{\circ} \text { ano) }\right.\end{array}$ \\
\hline & $\begin{array}{l}\text { 10.5. Os avanços tecnológicos, a melhoria nas } \\
\text { interpretações e as novas observações refinam } \\
\text { continuamente a nossa compreensão da Terra. }\end{array}$ & $\begin{array}{l}\text { 15. Compreender o contributo do conhecimento } \\
\text { geológico para a sustentabilidade da vida na Terra. }\left(7 .^{\circ}\right. \\
\text { ano) }\end{array}$ \\
\hline & $\begin{array}{l}\text { 10.6. Os cientistas em colaboração com os pro- } \\
\text { fessores podem selecionar os conhecimentos } \\
\text { básicos que favorecem a formação de cidadãos } \\
\text { alfabetizados em Ciências da Terra. }\end{array}$ & $\begin{array}{l}\text { Transversal a todos os conteúdos do } 2 .^{\circ} \text { e } 3 .^{\circ} \text { ciclos do } \\
\text { ensino básico (Bonito et al. 2013). }\end{array}$ \\
\hline
\end{tabular}

metas curriculares, com temáticas e propostas, não são suficientes em si mesmas. Cabe aos professores romper com paradigmas de ensino desajustados, de um ensino índole eminentemente teórico, integrando os novos contributos da psicologia cognitiva, através de metodologias ativas, participativas, que envolvam problemáticas locais e globais e a reflexão, o debate e a discussão na procura das possíveis soluções que sejam garante do bem-estar e da qualidade de vida atual e das gerações vindouras.

As metas curriculares relativas às Ciências da Terra preconizam um aluno cidadão geologicamente esclarecido, pró-ativo na sua comunidade e interessado nas questões atuais para as quais estas ciências podem dar um contributo expressivo. Recordamos, deste modo, o aforismo do Parque Nacional de Costa Rica: "Esta Tierra pertenence a todos los costarricenses. Algunos ya han muerto. Todavía vivimos, pero la mayoría aún no han nacido. Protegela”.

\section{Referências}

Barton C.C., La Pointe P.R. 1995. Fractales in Earth Sciences. New York: Springer Science-Business Media.

Bonito J. 2012. Panoramas atuais acerca do ensino das ciências. Boa Vista: Univ. Fed. Roraima.

Bonito J. 2014. Reorganização das metas curriculares no ensino básico Português: o caso das Geociências. Terrae Didatica, 10(3):227-239. (Anais Interfaces Geociências e Ensino: 40 anos de experiências (1973-2013), 23 e 24 de agosto de 2013, Campinas, SP, Brasil). URL: http://periodicos.sbu.unicamp.br/ojs/index.php/td/ article/view/8637327. Acesso 16.05.2017.

Despacho n. ${ }^{\circ}$ 5306/2012, de 18 de abril, do Ministro de Estado e das Finanças e do Ministro da Educação e Ciência. Diário da República, II Série, 77, 18 de abril de 2012. URL: http://dre.pt/pdf2sdip/2012/04/077000000/1395213953.pdf. Acesso 05.02. 2014.

Decreto-Lei n. ${ }^{\circ}$ 139/2012, de 5 de julho. Diário da República, I Série, 129, 5 de julho de 2012. URL: https:// 
dre.pt/application/file/a/178607. Acesso 21.01.2015.

GSA. The Geological Society of America. 2016. The importance of teaching Earth science. URL: https:// www.geosociety.org/documents/gsa/positions/pos4_ TeachingEarthScience.pdf. Acesso 5.06.2016.

Hargreaves A. 1998. Os professores em tempos de mudança: Trabalho e cultura dos professores na idade pós-moderna. Lisboa: McGraw-Hill.

Ministério da Educação. 2013. Metas curriculares. Ensino básico. Ciências Naturais. $5 .^{\circ}, 6^{\circ}, 7^{\circ}$ e $8 .^{\circ}$ anos. URL: http://dge.mec.pt/metascurriculares/index. php?s=directorio\&pid=22. Acesso: 05.02. 2014.

Ministério da Educação. 2017. Aprendizagens essenciais. URL: http://www.dge.mec.pt/aprendizagens-essenciais. Acesso: 21.08.2017.

NESTA. National Earth Science Teachers Association. 2015. The importance of Earth science Education K-12. URL: http://www.nestanet.org/cms/content/policy/ nestaposition\#imp. Acesso 14.9.2016.

Pedrinaci E., Alcaide S., Alfaro P., Almodóvar G., Barrera J.L., Belmonte A., Brusi D., Calonge A., Cardona V., Crespo-Blanc A., Feixas J.C., Fernández-Martínez E., González-Díez A., Jiménez-Millán J., López-
-Ruiz J., Mata-Perelló J.M., Pascual J.A., Quintanilla L., Rábano I., Rebollo L., Rodrigo A., Roquero E. 2013. Alfabetizazión en Ciencias de la Tierra. Enseñanza de las Ciencias de la Tierra, 21(2):117-129. URL: http://www.raco.cat/index.php/ECT/article/ view/274145/362238. Acesso 20.10.2014.

Rebelo D., Bonito J., Marques L., Morgado M., Trindade, V. Perspetivas sobre o ensino das Geociências no terceiro ciclo do ensino básico. 2017. In F. Veiga (coord), O Ensino como Fator de Envolvimento numa Escola para Todos. Lisboa: Climepsi Editores (em publicação).

Srivastava A., Nemani R., Steinhaeuser K. 2017. Largescale machine learning in the Earth Sciences. Florida: Taylor \& Francis Group.

Stewart S., Gill J. C. 2017. Social geology. Integrating sustainability concepts into Earth sciences. Proceedings of the Geologist's Association, 128(2):165-172.

UNESCO, 2008 Declaración presentada en el Acto Mundial de Inauguración del Año Internacional del Planeta Tierra (AIPT). URL: http://yearofplanetearth.org/content/ GLE/declaration/Declaration_Spanish.doc. Acesso 05.02. 2015.

Resumo: A literacia em Ciências da Terra do cidadão que conclui 0 ensino básico é, atualmente, considerada como um objetivo essencial para formular juízos de valor e tomar decisões acerca dos problemas que surgem quotidianamente na sociedade onde vive. Partindo das ideias-chave de uma Comissão Espanhola, criada para identificar os conhecimentos básicos em Ciências da Terra, faz-se uma sinopse com as metas curriculares para 0 ensino básico português relativas a conteúdos de Ciências da Terra. A análise efetuada permite constatar que Portugal tem definidos objetivos de aprendizagem para 0 ensino básico que 0 posicionam na vanguarda das propostas enquadradas nas ideias-chaves estabelecidas pela referida Comissão.

Palavras Chaves: Literacia, Educação em Ciências da Terra, metas curriculares, ensino básico. 